\title{
Pharmacovigilance: Present Scenario and Future Goals
}

\section{AK Mohiuddin}

\begin{abstract}
Pharmacovigilance is the science and activities associated with gathering, recognition, appraisal, checking, and counteractive action of untoward impacts with pharmaceutical items. Pharmacovigilance essentially safety of medicine. Pharmacists have key roles in wellbeing frameworks to keep up the reasonable and safe utilization of medicine for they are medicated specialists who are unequivocally prepared in this field. The perspective of drug store understudies on pharmacovigilance and adverse drug reaction (ADR) revealing has additionally been examined with an intend to center the need to improve content identified with ADR announcing and pharmacovigilance in undergrad drug store educational programs. Globally, despite the fact that the job of pharmacists inside national pharmacovigilance frameworks contrasts, it is exceptionally all around perceived. Reconciliation of ADR announcing ideas in instruction educational modules, preparing of pharmacists and deliberate commitment of pharmacists in ADR revealing is imperative in accomplishing the safety objectives and preservation of general wellbeing. Likewise, these learning holes can be placed through nonstop expert improvement projects and fortifying hypothetical and reasonable information in undergrade drug store educational programs. Without adequately distinguishing and acknowledging preparing requirements of pharmacists and other human services experts, the capability of national pharmacovigilance frameworks is probably not going to enhance which may trade off patient's safety.
\end{abstract}

Purpose: Discussion and projection of present situation analysis and future demand for pharmacovigilance. The pharmacists have a vital role to play which is thoroughly discussed.

Methodology: Research conducted a year-round comprehensive literature search, which included technical newsletters, newspapers journals, and many other sources. The present study was started at the beginning of 2018. PubMed, ALTAVISTA, Embase, Scopus, Web of Science, and the Cochrane Central Register of was thoroughly searched. The keywords were used to search for different publishers' journals like Elsevier, Springer, Willey Online Library, Wolters Kluwer extensively were followed. Medicine and technical experts, pharma company delegates, hospital nurses and chemists were given their valuable suggestions. Predictions were based on estimates such as drug end users, providers or prescribers, general knowledge of rational use, consequence and types of different incidences of ADR and

\section{Assistant Professor}

Department of Pharmacy, World University of Bangladesh, Bangladesh

Corresponding Author: AK Mohiuddin, Assistant Professor Department of Pharmacy, World University of Bangladesh, Bangladesh, Phone: 01716477485, e-mail: trymohi@gmail. com non-compliance, their management or overlooking. Studies regarding inclusion and information sources of pharmacovigilance were given priorities. Several factors that influence medication-taking behavior, non-compliance, ADR reporting by pharmacists were communally analyzed and added to the article. Issues regarding economic and cultural barriers were found to be different from subcontinents, countries and even states. Most significant features of pharmacists' role in the therapeutic intervention were added afterward to maintain a logical sequence. Drug factors, environmental factors and provider-patient interaction followed by pharmacist's role in handling patients and to change or correction of medication counseling, dispensing, monitoring was added to reveal their effect on patient compliance which is the eventual goal of meeting therapeutic guidelines. Many studies found regarding pharmacists' role in therapeutic cost minimization, role in hospital and other healthcare settings, disease prevention, and lifestyle management found to be not within the scope of this article.

Findings: Pharmacists are an integral part of the healthcare management system, and the importance of their role play is not after doctors and nurses. Any future role for the pharmacist in counseling, monitoring and vigilance could be addressed as part of a formalized, strategic approach by creating an integrated healthcare team, with attention to further enhancement of pharmacovigilance in any country, community or a healthcare setting.

Research limitations: Research has a major limitation with dealing too many information on pharmacovigilance worldwide. An only important aspect of the expanded role of pharmacists, the present situation of vigilance in different countries and a few future prospect, demand and provisions of pharmacists in meeting those emerging demands are discussed.

Practical implication: The soul of this article was to detail about the present situation and future demands of pharmacovigilance. Along with students, researchers and professionals of different background and disciplines, e.g., pharmacists, marketers, doctors, nurses, hospital authorities, public representatives, policy makers, and regulatory authorities have to acquire much from this article.

Social implication: The article should contribute an integrated guideline for patient compliance, demand pharmacovigilance and last but not the least a silver lining of better healthcare situation in near future.

Keywords: Adverse drug reactions, Medicine, Monitoring, Pharmacists, Prevention, Safety.

Abbreviations: Computerized provider order entry (CPOE); Clinical decision support (CDS); Drug-drug interactions (DDIs); Healthcare professionals (HCPs); Hypersensitivity drug reactions (HDRs); European medicines agency (EMA); Fatal adverse drug reactions (FADRs); Medicines use review (MUR); Uppsala monitoring centre (UMC); International society of pharmacovigilance (ISOP); Pharmacovigilance program of India (PvPI). 
How to cite this article: Mohiuddin AK. Pharmacovigilance: Present Scenario and Future Goals. Int J Res Foundation Hosp Healthc Adm 2018;6(2):91-98.

\section{Source of support: Nil}

Conflict of interest: None

\section{INTRODUCTION}

\section{World Health Organization}

World Health Organization (WHO) characterized pharmacovigilance as "the science and exercises identifying with the identification, appraisal, comprehension, and counteractive action of antagonistic impacts or some other medication-related issue". It is a vital and indistinguishable piece of clinical research. Both clinical preliminaries safety and post-showcasing pharmacovigilance (regularly known as post promoting studies or phase IV clinical preliminaries) are essential all through the item life cycle. With a sensibly high number of late prominent medication withdrawals, both the pharmaceutical business and in addition different administrative offices over the globe have expanded the bar. Early flag identification from the post-advertising observation thinks about and clinical preliminaries in early stages have now been adjusted by significant pharmaceutical organizations so as to recognize the dangers related with their therapeutic item/s as right on time as could be expected under the circumstances. An ADR is characterized by the WHO as "a toxic, unexpected impact of a medication that happens in portions regularly utilized in people for the conclusion, prophylaxis, and treatment of ailment". The indications of ADRs rely upon age, sex, hereditary, polypharmacy, portion exactness, and ecological and other interior variables like illness conditions. ADRs ordinarily answered in because of known or obscure pharmacological highlights, poor item quality (e.g., misleading, polluted, misbranded, fake, mediocre), prescription mistakes in recommending, getting ready, overseeing, or taking the medicine which requires hospitalization, causing critical handicap/ insufficiency, now and then hazardous and furthermore demise announced.

\section{Incorporation}

Pharmacovigilance is a procedure which incorporates:

- The observing of utilization of therapeutic items in regular clinical practice, to have the capacity to recognize already undisclosed unfriendly responses or an adjustment in the idea of unfavorable responses.

- Risk-advantage evaluation of restorative items, which picks what activity, if vital, is basic for a more secure utilization of therapeutic items.
- Providing data to human services experts and additionally to patients so as to enhance the protected and power utilization of therapeutic items.

\section{Wellsprings of Data in Pharmacovigilance}

Pharmacovigilance utilizes data from numerous sources:

- Natural detailing of unfavorable responses from medicinal services experts (connection to antagonistic responses)

- Clinical preliminaries and epidemiological investigations

- Published worldwide therapeutic writing

- Pharmaceutical organizations

- Healthcare and populace measurements

- Information on the utilization of restorative items

\section{Types and Prevalence of ADRs}

ADRs in hospitalized patients can be partitioned into two classes: those that are the reason for clinic confirmation, and those that happen amid hospitalization. There is restricted information on ADRs, particularly with respect to the responses that happen after confirmation. It is evaluated that ADRs happen in $10 \%$ of the overall public and 10 to $20 \%$ of in-patients, beyond what $15 \%$ of these ADRs can be lethal ${ }^{1,2}$ about 15 to $20 \%$ of ADRs relate to HDRs, which are actuated by presentation to a medication in a portion that is generally endured by solid people, and the responses are classified by target side effects that can be multiplied after resulting re-introduction. ${ }^{2}$ ADRs speak to an essential reason for dismalness and are thought to cause somewhere in the range of $10 \%$ and $30 \%$ of all healing center confirmations in more established patients. ${ }^{3}$ In the USA, over $90 \%$ of grown-ups matured multi-year and more seasoned utilize one prescription for every week and 10 to $25 \%$ experience an antagonistic medication response. ${ }^{4}$ These ADRs are responsible for $3-7 \%$ of healing facility confirmations. The predominance of ADRs was more in female patients when contrasted with men. ADRs generally happened in the age gathering of 41 to 50 years. ${ }^{5}$

\section{Value of Patient Reporting}

Patient announcing includes new data, and point of view about ADRs in a way generally inaccessible. This can add to better decision-making techniques in administrative exercises in the EU, there were 48,782 patient reports in 2015, showing an expansion of 30\% in $2014 .{ }^{6}$ Most patients did not know about detailing frameworks and others were befuddled about announcing. Patients were fundamentally propelled to make their ADRs known to turn away comparative enduring in different patients. By expanding patient associate and giving clear 
announcing procedures, revealing frameworks could more readily achieve patient detailing of ADRs. The WHO screens indiscreet ADR detailing in the greater part of nations. A typical issue is under-reporting. It is anticipated that just 5 to $10 \%$ of ADRs are accounted for. In spite of the fact that there is no gauge of patient revealing, 95\% of HCPs do not report ADRs. In 1976, a British doctor, Inman, was the first to distribute explanations behind under-reporting by HCPs, including:

- Contentment (believing that serious ADRs are well documented when the drug is released on the market)

- Fear of being involved in a lawsuit

- Guilt for having been responsible for damage observed in a patient

- Ambition to publish a case series or financial benefit

- Lack of awareness of the notification process

- Insecurity about reporting suspicions of an ADR

- Indifference ${ }^{7}$

\section{Value of Healthcare Professionals' Reporting}

The information collected during the premarketing phase is incomplete with regard to adverse drug reactions, and this is mainly because:

- Patients used in clinical trials are limited in number and are not illustrative to the public at large. In addition, the conditions of use of medicines differ from those in clinical practice and the period is limited.

- Information about rare but serious untoward reactions, chronic toxicity, and use in special groups (such as children, the elderly, or pregnant women) or drug interactions is often incomplete.

Consequently, post-showcasing reconnaissance is imperative to allow the location of less normal yet now and then intense ADRs. It is vital to allow the location of less normal yet in some cases intense ADRs. Wellbeing experts worldwide should give an account of ADRs as it can spare existences of their patients and others. ${ }^{8}$ Flag discovery is noteworthy to recognize the medication-related unfriendly impacts. Notwithstanding, the quantity of reports sent to national pharmacovigilance focuses is essential and additionally the nature of reports. The nature of reports is unquestionably predominant when they are filled by wellbeing experts who have pharmacology information, i.e., pharmacists, specialists, medical attendants, doctor collaborators, dental specialists and so on. It will be far and away superior in the event that it very well may be archived and recuperated from drug store data frameworks.

\section{Factors of ADR Reporting}

ADRs have emerged as a noteworthy clinical and general medical issue responsible for around 5 to $35 \%$ of healing center confirmations in both created and creating nations. In the US and EU, ADRs are among the main ten reasons for fleetingness and in addition rising the expense of consideration. The fast revealing of ADRs to medicate administrative bodies is a critical medication safety check yet under-detailing is a noteworthy test even in created nations with satisfactory human and material assets to stand up to the issue. ${ }^{9}$ Variables that may add to underreporting among HCPs incorporate learning, carelessness, the absence of time and drive. The absence of institutionalized revealing procedures and holes in human services data frameworks additionally causes underreporting. ${ }^{10}$ Studies recorded ADEs in outlines to help dauntlessness of consideration however never announced them to outside organizations. Suppliers confronted time imperatives, and detailing would have required duplication of documentation. ${ }^{11}$ Reviews of human services suppliers in intense healing centers have discovered that medical caretakers are bound to report episodes than specialists and that there are different subtleties for staff not revealing, including not realizing how to report events, time limitations, vulnerability about what to report, the desire for fault or discipline, and a discernment that detailing occurrences does not result in enhancements. ${ }^{12}$

\section{Biological Medicines Pose Specific Challenges for Pharmacovigilance}

An ongoing rule distributed by the EMA centers four key contemplations for the pharmacovigilance of biologicals; in particular, immunogenicity, fabricating fluctuation, solidness/chilly chain necessities, and item detectability. Organic medicines are the essential factors and albeit distinctive bunches of the equivalent natural medicine are not alike, the nature of each cluster is firmly controlled to guarantee the safety and adequacy of the medicine. In any case, required assembling process changes can affect quality characteristics of the organic and this can happen unbeknownst to medicinal services experts and patients. In uncommon cases, these progressions can affect the immunogenicity of an item. Natural medicines including biosimilars are ending up logically accessible. Biosimilars are unmistakable from the generics of synthetic medicines as, attributable to the troubles of natural substances and their assembling forms, and biosimilars are not totally indistinguishable to the first medicine on which they are based (reference medicine). The likeness to the reference medicine is set up through a thorough equivalence practice guided at the quality, pre-clinical and clinical dimensions. All recently affirmed natural medicines, including biosimilars, are liable to additionally checking for a time of 5 years after endorsement. ${ }^{10}$ 


\section{Medical and Economical Burden of ADRs}

The therapeutic weight of FADRs is noteworthy. The most critical concerns are recommended medicines, oversight of essential treatment, inability to screen treatment and poor frameworks. These were identified with imperfections in instruction or preparing, the absence of clear rules or conventions and inability to invention existing rules, among different reasons. ${ }^{13}$ An expected 106,000 deaths expressed somewhere in the range of 1966 and 1996 in the US. Be that as it may, it is evaluated that just $6 \%$ of ADRs are accounted for. ${ }^{2}$ What's more, half 70\% are accepted avoidable. An anticipated 197,000 deaths for each year in the EU are caused by ADRs, and the aggregate expense to society of ADRs in the EU is $€ 79$ billion. ADRs exemplify the fifth most regular reason for death in a healing center setting. ${ }^{14}$ In intensely sick grownups, superb proof demonstrates that liberal oxygen treatment expands mortality without enhancing other patient-imperative results. ${ }^{15}$ Somewhere in the range of 1976 and 2007, 28 drugs were pulled back from the US to advertise for safety reasons. ${ }^{16}$ Death rates due to ADRs are evaluated from 0.1 to $2.9 \%$. An intelligent eight-year (1999-2006) examine led in the US of $>2$ million deaths uncovered that 2341 death $(0.1$ per 100,000) were ADRrelated deaths. In 2005, drugs were the main source of death evaluated at 739, 936 every year. ${ }^{17}$ The anticipated aggregate money related expense of $\$ 17.88$ billion speaks to $1.55 \%$ of Australian total national output. ${ }^{18}$

\section{Pharmacovigilance in Healthcare Education}

Social insurance experts have little cognizance of pharmacovigilance and ADR revealing, and just a couple of instructive associations effectively affected this mindfulness. Future human services suppliers ought to along these lines obtain a sufficient arrangement of pharmacovigilance capabilities to normally recommend, circulate, and screen drugs. Anticipating, diagnosing, overseeing, and detailing ADRs are a critical piece of normal and safe recommending and are acclimatized into various strides of the WHO-six-advance Guide to Good Prescribing. ${ }^{19}$ Various examinations have communicated worry about the absence of medicinal services proficient skills in pharmacovigilance. ${ }^{20,21}$ This absence of undergrade instruction and preparing in pharmacovigilance is predictable with the low dimension of information, abilities, and activities seen in doctors as well as in rehearsing pharmacists, dental practitioners, and medical attendants. ${ }^{22-24}$ Newness to pharmacovigilance, a low dimension of ADR-detailing abilities, an absence of learning joined with negative demeanors like obliviousness, fear legitimate risk, and absence of significance are believed to be identified with the current deficient reaction to numerous ADRs. ${ }^{25-28} \mathrm{~A}$ few medications (actualizing conventions, instructive workshops, or continued messaging or phone calls) have been executed trying to enhance the fitness of social insurance experts, ${ }^{29-32}$ yet these intercessions are exorbitant or neglect to deliver clinically applicable and long-haul impacts. ${ }^{23}$

\section{Pharmacovigilance in Pharmaceutical Industries}

The aims of pharmacovigilance within the industry are essentially the same as those of regulatory agencies; that is to protect patients from unnecessary harm by identifying previously unrecognized drug hazards, elucidating pre-disposing factors, refuting false safety signals and quantifying risk in relation to benefit. Although the perspectives of companies and the regulatory agencies may be different, they now work more and more closely together and share information. ${ }^{33}$

\section{Worldwide Monitoring of Pharmacovigilance}

In 2002, in excess of 65 nations have their own pharmacovigilance focuses. Enrollment of the WHO for International Drug Monitoring is facilitated by the WHO Collaborating Center for International Drug Monitoring, known as the UMC. Pharmacovigilance is presently solidly dependent on sound logical standards and is basic to successful clinical practice. The order needs to grow further to meet open desires and the requests of current general wellbeing. A mind-boggling and indispensable relationship exists between wide scopes of accomplices in the act of medication safety checking.

- Quality Assurance and Safety: The group is a piece of the Department of Essential Drugs and Medicines Policy, inside the WHO Health Technology and Pharmaceuticals bunch. ${ }^{34}$

- UMC, Sweden: A free, not-revenue driven establishment, a middle for universal logical research, situated in Sweden-firmly related to WHO, since 1978. The chief capacity of the UMC is to deal with the universal database of ADR reports got from National Centers. ${ }^{35}$

- National Pharmacovigilance Centers: National Centers have assumed a vital job in expanding open attention to tranquilize safety. This advancement is somewhat owing to the way that numerous national and local focuses are housed inside doctor's facilities, restorative schools or toxic substance and medication data focuses, as opposed to inside the points of confinement of a medication administrative expert. ${ }^{36}$

- Hospitals: various medicinal foundations have progressed ADRs and drug blunder close watch frameworks in their centers, wards, and crisis rooms. 
- Academia: Academic focuses of pharmacology and drug store have assumed a vital job through instructing, preparing, look into, strategy improvement, clinical research, morals councils (institutional survey sheets) and the clinical administrations they give. ${ }^{37}$

- Health Professionals: Originally doctors were the main experts welcomed to report as making a decision about whether sickness or medicine causes a specific side effect by practicing the aptitude of differential determination. ${ }^{38}$

- Patients: Only a patient knows the genuine advantage and mischief of medicine taken. Coordinate patient investment in the revealing of medication-related issues will build the proficiency of the pharmacovigilance framework and make up for a portion of the inadequacies of frameworks dependent on reports from wellbeing experts as it were.

\section{Necessity of Collaboration}

Pharmacovigilance framework usage is the need which is conceivable by a joint effort between the scholarly world, human services suppliers including a pharmacist, patient, maker, government, media, and common society, UMC Sweden working under WHO, FDA, ISOP and other worldwide association taking a shot at medication safety. ${ }^{39}$ There are five WHO Collaborating Centers working for pharmacovigilance, each in pro regions. Notwithstanding UMC in Sweden, these are in India, Morocco, the Netherlands, and Norway.

- The focus in Rabat (Morocco): Became a WHO Collaborating Center in 2011. The Rabat focus underpins WHO by building limit in the WHO Eastern Mediterranean Region, in francophone, and Arabic nations.

- Pharmacovigilance Center Lareb (Netherlands): Netherlands' national pharmacovigilance community for Pharmacovigilance in Education and Patient Reporting. It turned into a WHO Collaborating Center in 2013.

- The Center in Norway was built up in 1982 in Oslo at the Department of Pharmacoepidemiology at the Norwegian Institute of Public Health, sponsored by the Norwegian Government.

- Founded in 2010, the PvPI was assigned as an expert focus by WHO in Geneva, 2017. ${ }^{40,41}$

\section{Role of Pharmacist in the Management of ADRs}

In the United States alone, DDIs add to $20 \%$ everything being equal, which cause about 770,000 passings and result in $\$ 30$ billion to $\$ 180$ billion in human services costs and four hospitalizations for every 1,000 individuals yearly. A pharmacist assumes a pivotal job in the distinguishing proof, location, counteractive action, and the board of DDIs, sedate sustenance collaborations and ADRs. ${ }^{42,43}$ The pharmacist can complete such exercises in the inpatient setting, while at the same time partaking in survey diagrams amid ward rounds, and amid drug the executives while managing solutions.

The prevalence of patients who visited different healing facilities with the equivalent or comparable condition was about $40 \%$ among patients going to government outpatient divisions in Hong Kong, 23\% among essential consideration patients in Japan, and $23.5 \%$ among outpatients in Taiwan. ${ }^{44}$ Patients who get restorative consideration from various human services suppliers, especially from various healing centers, are bound to endure ADRs. A few scientists suggested that pharmacists use mechanized screening programming to distinguish potential medication treatment issues and avert unfavorable occasions. Others proposed utilization of CPOE with CDS to recoup medicine mistakes.

The intercession of pharmacists by sorting out addresses and gathering dialogs in this way giving data about the significance, earnestness, preventability, and stipulation of revealing shows increased enhancement of learning, demeanor, and discernment about ADRs.

All wellbeing experts assume their particular jobs in adjusting among advantages and dangers of prescription when it is presented in the market. Be that as it may, the aptitude of a pharmacist about a medication, particularly if recently advertised, assume a progressively huge job in ADRs answering to the experts which help in either withdrawing the item from the market or cause naming changes. ${ }^{45}$ Following thalidomide-induced phocomelia catastrophe, Bowles asked ADR revealing as a factor in the underwriting of pharmacists in $1964 .{ }^{46}$

Pharmacists working in network drug store have an additional advantage of distinguishing and revealing ADRs while managing on the counter medicines and natural items. In a network drug store, a pharmacist might not have immediate and unmistakable patient rundown but rather the patients going to a similar drug store to refill their remedy offers the pharmacist a chance to identify a conceivable ADR that the patient may understanding and can help in the administration and the detailing of the said ADR. Pharmacist conference aptitudes should be assessed if MURs are to understand their imagined points. ${ }^{47}$

\section{Role of Pharmacist in Pharmacovigilance}

The commitment of the pharmacist to pharmacovigilance should be that as it may, not be restricted to ADR announcing. Particularly, healing facility pharmacists can assume a huge job in ADR announcing on the grounds that the most genuine antagonistic medication occasions happen 
in doctor's facilities, and ADRs represent a significant extent of doctor's facility confirmations. ${ }^{48}$ The pharmacist could be an organizer between various individuals from social insurance group and the patients, to guarantee both carefulness and consistency. Along these lines, support of pharmacists in wellbeing the executive's framework is ending up extremely crucial step by step. Pharmacists are associated with conveying social insurance offices and in addition proposing therapeutic staff on a legitimate collection of medications. They additionally plan, screen and assess medicate projects to upgrade wellbeing and diminish wellbeing aberrations. ${ }^{49,50}$ Healing facility pharmacists guarantee that medicines are overseen securely and adequately with the goal that they are suitable for the age, sex, body weight and clinical status of the patient. Network pharmacists then again come in direct contact with the general population, and they apportion drugs as well as guidance's patients seeing general wellbeing themes, for example, diet, work out, push the executives, over-the-counter prescriptions and so forth. ${ }^{51,52}$ Some people group pharmacists additionally furnish specific administrations to assist patients with diabetes, asthma, smoking suspension, chronic drug use, and patients with hypertension. The job of pharmacists in pharmacovigilance frameworks is expanded under Affordable Care Act or the present social insurance change, since individuals who generally had no protection, presently meet all requirements for protection; and this could build the case for drug store administrations. More pharmacists will be required in conveying wellbeing training, including instruction on DDIs. ${ }^{53}$ Pharmacists can forestall sedate association, a direct patient with respect to the sickness and prescription, e.g. giving data, guidance, and support about medicine and treatment because of their entrance of relational correspondence. The changing job of the pharmacist from conventional 'tranquilize gadget' idea towards 'pharmaceutical consideration supplier' extended the job of pharmacists. In this way, pharmacists can assume a key job in deflecting drug maltreatment by giving clear data about the antagonistic impacts of prescriptions. ${ }^{54}$ Plus, the advancement of electronic data frameworks has been an earth-shattering in distinguishing and interceding drug-related issues, for example, dose, unfriendly responses, associations, consistency or inadequacy.

\section{CONCLUSION}

Being drug master and coach of sheltered and compelling medication use, pharmacists have critical pretend in identification, report, observing alongside avoidance of ADRs. The absence of anxiety still exists among pharmacists who are restricted to change from item situated to patient arranged. The hole can be limited through proceeded with expert improvement programs and in addition fortifying information base in undergrad level. A strengthening and commitment of network pharmacists to patient record check and electronic announcing may likewise lessen ADR related occasions. Without successful distinguishing proof and satisfaction of preparing needs of pharmacists and other medicinal services experts, the effectiveness of national pharmacovigilance frameworks is probably not going to enhance, which may bargain patient safety. To achieve this objective, administrative bodies should make enactments to rouse pharmacists to be effectively engaged with the framework. Other than their dynamic cooperation, their allotted job ought to have a more extensive range to acquire the greatest help dependent on their aptitude. Compelling utilization of pharmacists' workforce will enhance the result of the pharmacotherapy and in addition decline worldwide wellbeing costs.

\section{ACKNOWLEDGMENT}

It's an extraordinary appreciation and respect to be a piece of social insurance research and training. Pharmacists of all teaches that I have led was especially useful in talking about pharmacovigilance circumstance at the home and abroad, giving books, diaries, bulletins and valuable time. The best help was from my understudies who paid enthusiasm for my subject as class address and urged to compose such article including ADR the board and pharmacovigilance. In spite of an extraordinary shortage of subsidizing this reason from an expert, the experience was sufficient to continue to inquire about.

\section{REFERENCES}

1. Öztürk AB, Özyiğit LP, Şener Ü, Özyıldırım A, İliaz S, Çağlayan $B$, et al. Reporting Adverse Drug Reactions in a Tertiary Care Hospital in İstanbul. Turk Thorac J. 2018;19(4):237-239.

2. Ribeiro MR, Motta AA, Marcondes-Fonseca LA, Kalil-Filho J, Giavina-Bianchi P. Increase of $10 \%$ in the Rate of Adverse Drug Reactions for Each Drug Administered in Hospitalized Patients. Clinics (Sao Paulo). 2018;73:e185.

3. Parameswaran Nair N, Chalmers L, Peterson GM, Bereznicki BJ, Castelino RL, Bereznicki LR. Hospitalization in older patients due to adverse drug reactions -the need for a prediction tool. Clin Interv Aging. 2016;11:497-505.

4. Ruscin JM, Linnebur SA. Aging and Drugs. Merck Manual Consumer Version. ( 2018 Merck Sharp \& Dohme Corp., a subsidiary of Merck \& Co., Inc., Kenilworth, NJ, USA.

5. Chopra D, Rehan HS, Sharma V, Mishra R. Chemotherapyinduced adverse drug reactions in oncology patients: A prospective observational survey. Indian J Med Paediatr Oncol. 2016 Jan-Mar;37(1):42-46.

6. Inácio P, Cavaco A, Airaksinen M. The value of patient reporting to the pharmacovigilance system: a systematic review. Br J Clin Pharmacol. 2016;83(2):227-246. 
7. Al Dweik R, Stacey D, Kohen D, Yaya S. Factors affecting patient reporting of adverse drug reactions: a systematic review. Br J Clin Pharmacol. 2016;83(4):875-883.

8. Gurmesa LT, Dedefo MG. Factors Affecting Adverse Drug Reaction Reporting of Healthcare Professionals and Their Knowledge, Attitude, and Practice towards ADR Reporting in Nekemte Town, West Ethiopia. Biomed Res Int. 2016;2016:5728462.

9. Avong YK, Jatau B, Gurumnaan R, Danat N, Okuma J, Usman I, et al. Addressing the under-reporting of adverse drug reactions in public health programs controlling HIV/AIDS, Tuberculosis and Malaria: A prospective cohort study. PLoS One. 2018;13(8):e0200810. 2018 Aug 22.

10. O'Callaghan J, Griffin BT, Morris JM, Bermingham M. Knowledge of Adverse Drug Reaction Reporting and the Pharmacovigilance of Biological Medicines: A Survey of Healthcare Professionals in Ireland. Bio Drugs. 2018;32(3): 267-280.

11. Hohl CM, Small SS, Peddie D, Badke K, Bailey C, Balka E. Why Clinicians Don't Report Adverse Drug Events: Qualitative Study. JMIR Public Health Surveill. 2018;4(1):e21. 2018 Feb 27.

12. Gifford ML, Anderson JE. Barriers and motivating factors in reporting incidents of assault in mental health care. J Am Psychiatr Nurses Assoc. 2010 Sep;16(5):288-298.

13. Ferner RE, Easton C, Cox AR. Deaths from Medicines: A Systematic Analysis of Coroners' Reports to Prevent Future Deaths. Drug Saf. 2018 Jan;41(1):103-110.

14. Giardina C, Cutroneo PM, Mocciaro E, Russo GT, Mandraffino G, Basile G, et al. Adverse Drug Reactions in Hospitalized Patients: Results of the FORWARD (Facilitation of Reporting in Hospital Ward) Study. Frontiers in pharmacology. 2018 Apr 11;9:350.

15. Chu DK, Kim LH, Young PJ, Zamiri N, Almenawer SA, Jaeschke R, et al. Mortality and morbidity in acutely ill adults treated with liberal versus conservative oxygen therapy (IOTA): a systematic review and meta-analysis. Lancet. 2018 Apr 28;391(10131):1693-1705.

16. Wilke RA, Lin DW, Roden DM, Watkins PB, Flockhart D, Zineh I, et al. Identifying genetic risk factors for serious adverse drug reactions: current progress and challenges. Nat Rev Drug Discov. 2007;6(11):904-916.

17. Angiji A. Adverse Drug Reactions related to mortality and morbidity: Drug - drug interactions and overdoses.

18. Hillman D, Mitchell S, Streatfeild J, Burns C, Bruck D, Pezzullo L. The economic cost of inadequate sleep. Sleep. 2018 Jun 4;41(8):zsy083.

19. Hartman J, Härmark L, van Puijenbroek E. A global view of undergraduate education in pharmacovigilance. Eur J Clin Pharmacol. 2017;73:891-899.

20. Abubakar AR, Haque M. Pharmacovigilance practice: the current challenges and the gaps in the medical students' curriculum. J App Pharm Sci. 2016;6(05):210-215.

21. Gavaza P, Bui B. Pharmacy students' attitudes toward reporting serious adverse drug events. Am J Pharm Educ. 2012;76(10):194.

22. De Angelis A, Colaceci S, Giusti A, Vellone E, Alvaro R. Factors that condition the spontaneous reporting of adverse drug reactions among nurses: an integrative review. J NursManag. 2015;23(4):1-13.

23. Pagotto C, Varallo F, Mastroianni P. Impact of educational interventions on adverse drug events reporting. Int J Technol Assess Health Care. 2013;29(4):410-417.
24. Rutter P, Brown D, Howard J, Randall C. Pharmacists in pharmacovigilance: can increased diagnostic opportunity in community settings translate to better vigilance? Drug Saf. 2014;37(7):465-469.

25. Gonzalez-Gonzalez C, Lopez-Gonzalez E, Herdeiro MT, Figueiras A. Strategies to improve adverse drug reaction reporting: a critical and systematic review. Drug Saf. 2013;36(5): 317-328.

26. Lopez-Gonzalez E, Herdeiro MT, Figueiras A. Determinants of under-reporting of adverse drug reactions: a systematic review. Drug Saf. 2009;32(1):19-31.

27. Inman $\mathrm{WH}$. Attitudes to adverse drug reaction reporting. $\mathrm{Br}$ J Clin Pharmacol. 1996;41(5):434-435.

28. De Angelis A, Colaceci S, Giusti A, Vellone E, Alvaro R. Factors that condition the spontaneous reporting of adverse drug reactions among nurses: an integrative review. Journal of nursing management. 2016 Mar;24(2):151-163.

29. Herdeiro MT, Ribeiro-Vaz I, Ferreira M, Polnia J, Falco A, Figueiras A. Workshop-and telephone-based interventions to improve adverse drug reaction reporting: a clusterrandomized trial in Portugal. Drug Saf. 2012;35(8):655-665.

30. Johansson-Pajala RM, Martin L, Fastbom J, Blomgren KJ. Nurses' self-reported medication competence in relation to their pharmacovigilant activities in clinical practice. J Eval Clin Pract. 2015;21(1):145-152.

31. Ribeiro-Vaz I, Santos CC, Cruz-Correia R. Promoting adverse drug reaction reporting: comparison of different approaches. Rev Saude Publica. 2016;50:14.

32. Ribeiro-Vaz I, Herdeiro MT, Polónia J, Figueiras A. Strategies to increase the sensitivity of pharmacovigilance in Portugal. Revista de saude publica. 2011 Feb;45(1):129-135.

33. Talbot JC, Nilsson BS. Pharmacovigilance in the pharmaceutical industry. Br J Clin Pharmacol. 1998;45(5):427-431.

34. WHO Medicines Strategy: Framework for Action in Essential Drugs and Medicines Policy 2000-2003.

35. Olsson S. The role of the WHO Programme for International Drug Monitoring in coordinating worldwide drug safety efforts. Drug Saf. 1998;19:1-10.

36. Coulter DM. The New Zealand intensive medicines monitoring programme in proactive safety surveillance. Pharmacoepidemiol Drug Saf. 2000;9:273-280.

37. Moore N. The role of the clinical pharmacologist in the management of ADRs. Drug Saf. 2001;24:1-7.

38. Hornbuckle K, Wu HH, Fung MC. Evaluation of spontaneous adverse event reports by primary reporter: A 15-year review (1983 to 1997) Drug Inf J. 1999;33:1117-1124.

39. Mahmood KT, Amin F, Tahir M, Haq IU. Pharmacovigilance-A need for best patient care in Pakistan. A review. Journal of Pharmaceutical Sciences and Research. 2011 Nov 1;3(11): 1566-1584.

40. Uppsala Monitoring Centre (UMC) Web. WHO Collaborating Centres 2017; Nov 13.

41. WHO Web. The Importance of Pharmacovigilance-Safety Monitoring of Medicinal Products 2002. Essential Medicines and Health Products Information Portal A World Health Organization resource.

42. Peabody J, Acelajado MC, Robert T, Hild C, Schrecker J, Paculdo D, Tran M, Jeter E. Drug-drug interaction assessment and identification in the primary care setting. Journal of clinical medicine research. 2018 Nov;10(11):806-814.

43. Ansari J. Drug interaction and pharmacist. J Young Pharm. 2010;2(3):326-331. 
44. Yeh YT, Hsu MH, Chen CY, Lo YS, Liu CT. Detection of potential drug-drug interactions for outpatients across hospitals. Int J Environ Res Public Health. 2014;11(2):1369-1383.

45. Shah RR. Importance of Publishing Adverse Drug Reaction Case Reports: Promoting Public Health and Advancing Pharmacology and Therapeutics. Drug Saf Case Rep.2017;4(1):11.

46. Bowles Jr GC. Adverse drug reaction reporting urged as factor in accreditation. Mod Hosp. 1964;103:120.

47. Latif A,Helen P, Boardmana F. The contribution of the Medicines Use Review (MUR) consultation to counseling practice in community pharmacies. PatientEducation and Counseling 2011 June 83(3):336-344.

48. Van Grootheest AC, De Jong-van den Berg LT. The role of hospital and community pharmacists in pharmacovigilance. Res Social Adm Pharm. 2005 Mar;1(1):126-133.
49. APhA. Principles of Practice for Pharmaceutical Care. (C) Copyright 2018, American Pharmacists Association.

50. Mohiuddin AK. Patient Compliance: An Untold Story or a Fairy Tale. Pharmaceut Reg Affairs. 2018;7(2):207.

51. Kumar B, Khare DP, Shafaat K, Yadav VK, Kumar U. Professional scopes and roles of community pharmacists in various health care services: An updated review. Journal of Pharmacy Research 2011,4(5):1331-1335.

52. Bhaskaran S. A vision of Indian pharmacist in 2020. PHARMABIZ.com December 16, 2010.

53. Toklu HZ, Mensah E. Why do we need pharmacists in pharmacovigilance systems?. Online J Public Health Inform. 2016;8(2):e193.

54. Management Sciences for Health (www.msh.org). Chapter 33. Encouraging appropriate medicine use by consumers. 